\title{
Research on Fuzzy Reliability Prediction Method of CNC Machine Tools
}

\author{
G.B. Zhang \\ College of Mechanical Engineering \\ Chongqing University \\ Chongqing, china \\ D.M. Luo \\ College of Mechanical Engineering \\ Chongqing University \\ Chongqing, china
}

\author{
Y. Ran \\ College of Mechanical Engineering \\ Chongqing University \\ Chongqing, china \\ W. Yu \\ College of Mechanical Engineering \\ Chongqing University \\ Chongqing, china
}

\begin{abstract}
Traditionally the reliability data is very insufficient in the early designing stage of CNC machine tools and the factors that affect reliability prediction are complicated and fuzzy. So, in this paper, a fuzzy comprehensive evaluation model based on vague set algorithm (VSA) is proposed for reliability prediction. Firstly, the GO methodology is used to establish the system reliability model of $\mathrm{CNC}$ machine tools. Secondly, the reliability prediction model is built based on vague set. Finally, an example of rotary table in machining center is taken to prove the availability of the model. Considering the four chief influence factors (design, test, manufacture and maintenance), the VSA model is adopted to make quantitative analysis and prediction, by which the feasibility and applicability of the proposed method are verified, and simultaneously the references are provided for the reliability design of next stage.
\end{abstract}

Keywords-CNC machine tools; reliability prediction; vague set; GO methodology

\section{INTRODUCTION}

Reliability prediction is the main component of system reliability design, which is generally used to pre-estimate whether the designed system, can achieve the specified reliability requirements under the given operating condition. It is of great influence to product planning, maintenance decision, reliability as sessment, the fault detection and risk evaluation of the manufacturing process [1]. However, the reliability data is seriously insufficient during the initial design stage, and the factors that affect the reliability prediction are complicated and fuzzy. Therefore it is difficult to deal with such item with fuzzy uncertainty.

According to the property that the fuzzy numbers are suitable for quantifying fuzzy information, Zhao et al. proposed an approach of multi-stage fuzzy synthetic as sessment based on fuzzy numbers [2]. Hao et al. presented a reliability prediction method introducing interval analytic hierarchy (AHP), which exhaustively analyzed the difference between the evaluation object and the similar product, and realized the mutual complement of certain and fuzzy information [3]. Chen et al. proposed an electronic equipment reliability prediction method (EERPM) combined with functional analysis and physics of failure [4]. Ren et al. did a research on the CNC reliability prediction based on grey system theory [5]. Zhao et al. put forward a mechanical reliability prediction based on fuzzy comprehensive and fuzzy inference method [6]. The methods above extraordinarily depend on the basic sample data. But the data insufficient is serious in the initial design stage of machine tools, coupled with many uncertain factors, which made all the methods above inapplicable. Vague set [7], the generalization of the fuzzy set, is more intuitive and operable, also has an advantage over analyzing and handling of the fuzzy problems. In addition, it can sufficiently exploit the experts' advices, and improve the rationality of the comprehensive evaluation.

On account of the above analys is, this paper presents a fuzzy comprehensive evaluation model based on vague set. Moreover, it offers a possibility for handling the data deficiency and fuzzy decision-making of the traditional models.

\section{THE RELIABILITY MODELING OF CNC MACHINE TOOLS}

There are three steps in reliability prediction of $\mathrm{CNC}$ machine tools: firstly it is necessary to establish a relationship model among the various subsystems; secondly the predicted reliability degree of each subsystem should be calculated; and finally the predicted reliability degree of the whole machine can be obtained. Based on the principle of the GO methodology [8], GO chart is used to represent the relationship among subsystems and whole machine for the reliability analysis, as shown in Figure 1. 


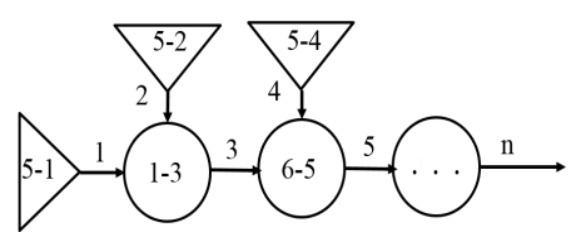

FIGUREI. THE GO CHART MODEL FOR THE SYSTEM.

The system reliability model of $\mathrm{CNC}$ machine tools is shown as

$$
R_{S}=P_{S}=P_{S}(0) \prod_{i=1}^{n} P_{S}(i) \prod_{i=1}^{n} P_{C}(i)
$$

Where $P_{S}(0)$ is the reliability degree of the system input, $P_{C}(i)$ is the reliability degree of each subsystem, $P_{S}(i)$ stands for the control signal and $n$ is the number of the subsystems.

On the basis of the reliability GO chart of the system, the reliability prediction process of CNC machine tools using VSA is shown in Figure 2.

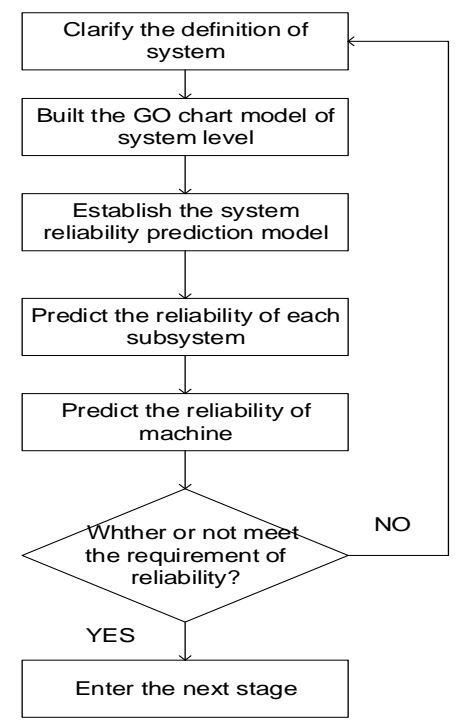

FIGUREII. FLOW CHART FOR RELIABILITY PREDICTION OF CNC MACHINE TOOLS.

\section{The Reliability PREDICTION MODEL BASED ON VAGUE SET}

Vague set is defined as $\hat{A}(x)=\left[t_{A}(x), 1-f_{A}(x)\right]$, $\hat{A}(x) \in[0,1]$, where $t_{A}(x)$ is the lower bound of membership derived from the evidences in support of $\mathrm{x}$, $f_{A}(x)$ denotes the lower bound of non-membership exported from the evidences against $x$, and $t_{A}(x)+f_{A}(x) \leq 1$ [9]. Then the fuzzy synthesis reliability prediction process based on vague set in this paper is as follows.

\section{A. Influence Factor Set Building}

In the reliability prediction of $\mathrm{CNC}$ machine tools, the four influence factors: design, test, manufacture and maintenance, are respectively expressed by $\mathrm{U}_{1}, \mathrm{U}_{2}, \mathrm{U}_{3}, \mathrm{U}_{4}$. The influence factors can be increased or decreased depending on specified object of study. The influence factor set in reliability prediction of $\mathrm{CNC}$ machine tools is built as follows.

$$
\mathrm{U}=\left\{\mathrm{u}_{1}, \mathrm{u}_{2}, \mathrm{u}_{3}, \mathrm{u}_{4}\right\}
$$

\section{B. Factor Weight set Establishment}

Essentially the weights of factors just reflect the relative importance in the process of evaluation, so the weight set is considered as follows.

$$
\tilde{\mathbf{W}}=\left\{\mathrm{w}_{1}, \mathrm{w}_{2}, \mathrm{w}_{3}, \mathrm{w}_{4}\right\}
$$

(1) Set the rating scale and its benchmark score,

$$
X=\left\{x_{1}, x_{2}, \ldots, x_{k}\right\}
$$

Where $\mathrm{X}_{\mathrm{j}}$ is the benchmark score of the $j$ th rating scale.

The weights of factors are determined by $m$ experts in accordance with the integrated voting model, and expressed by vague values. The possible range of the factor $u_{i}$ 's weight belonging to the rating scale is as follows

$$
\hat{P}_{i j}=\left\{\left[t_{i j}, 1-f_{i j}\right] ; \alpha_{i j}\right\}
$$

Where $i=1,2, \ldots, n ; j=1,2, \ldots, k, \alpha_{i j}$ stands for the possibility of nonvoters tending to cast an affirmative vote, which is named as propensity score.

(2) Calculate the satisfaction degree of $\hat{P}_{i j}$, namely to es timate the fuzzy membership, and then get the estimated value $\mathrm{D}_{\mathrm{ij}}(\mathrm{x})$

$$
D_{i j}(x)=t_{i j}(x)+\alpha_{i j} \times\left[1-t_{i j}(x)-f_{i j}(x)\right]
$$

(3) Calculate the basic weights of the factors. In order to synthesize the decision information of experts, the weighted average method is used here. Considering the estimated value $D_{i j}(x)$ as the weights, each rating scale ${ }^{x_{i}}$ is weighted, by which the obtained value is used as the basic weight of factor. Thus the basic weight of factor ${ }^{i}$ can be got.

$$
z_{i}=\sum_{j=1}^{k} D_{i j} x_{j} / \sum_{j=1}^{k} D_{i j}
$$

(4) Normalization processing is carried out on the basic weight $z_{i}$, getting the weight set $\tilde{\mathbf{W}}=\left(\mathbf{W}_{1}, \mathbf{w}_{2}, \ldots, \mathbf{w}_{\mathrm{n}}\right)$ and 


$$
w_{i}=z_{i} / \sum_{i=1}^{n} z_{i}
$$

Since fuzzy set is the special case of vague set, the weight can also be referred as $\hat{W}=\left(w_{1}, w_{2}, \ldots, w_{n}\right)$.

\section{Alternative Set Establishment}

Alternative domain contains the reliability degree range which may be possessed by the subsystems, so the alternative set is the set of subsystem reliability degree. Roughly estimate the reliability degree of the object, then take this as the alternative domain. Discretize the continuous domain into $m$ values, which are regarded as alternative elements, and the the alternative set can be obtained.

$$
\mathrm{V}=\left\{\mathrm{v}_{1}, \mathrm{v}_{2}, \ldots, \mathrm{v}_{\mathrm{m}}\right\}
$$

\section{Comprehensive Evaluation}

Comprehensive evaluation requires that experts should vote for whether the predicted object is taken as the alternative element $V_{i}$ based on each sub-factor of all factors. After getting the alternative element's membership, the relationship between factor subset and alternative set will be changed to fuzzy relation from vague one.

The membership of the predicted object belonging to the alternative element $v_{j}$ in the evaluation of factor $U_{i}$ is set up as $r_{i j}(i=1,2,3,4 ; j=1,2,3, \ldots, m)$.

So the evaluation matrix is

$$
\tilde{R}=\left[\begin{array}{cccc}
r_{11} & r_{12} & \cdots & r_{1 m} \\
r_{21} & r_{22} & \cdots & r_{2 m} \\
\vdots & \vdots & \vdots & \vdots \\
r_{41} & r_{42} & \cdots & r_{4 m}
\end{array}\right]
$$

Then the factor $\mathrm{u}_{\mathrm{i}}$ is comprehensively evaluated, using the weighted average algorithm.

$$
\tilde{B}=\tilde{W} \circ \tilde{R}=\left(b_{1}, b_{2}, \ldots, b_{m}\right)
$$

Weighted average is brought forward to the comprehensive indexin order to get the value of reliability prediction afterwards.

$$
P_{C}=\sum_{j=1}^{m} b_{j} v_{j} / \sum_{j=1}^{m} b_{j}
$$

The reliability prediction values of all subsystems can be got in accordance with the above steps. Finally the predicted reliability of CNC machine tools can be obtained with all the values calculating in Eq. (1).

\section{CASE ANALYSIS}

Based on the analysis of systemstructure, $\mathrm{CNC}$ machine tool can be divided into 14 modules, including basic components, NC rotary table, pallet changer, ATC, headstock, gearing, hydraulic system, pneumatic system, lubrication system, cooling system, chip-removal system, protective system, joint interface and electrical system. The systemreliability GO chart is shown in Fig. 1 , with the number of subsystem $n=14$. Here NC rotary table is taken as an example, and considering the four factors of design, test, manufacture and maintenance, the fuzzy comprehensive evaluation based on vague set is adopted to predict the reliability of the rotary table.

Set up the evaluation criterion firstly. The rating is assumed as 4 grades here: common, less important, important, more important, which are given corresponding benchmark scores.

$$
X=\left\{x_{1}, x_{2}, x_{3}, x_{4}\right\}=\{2,4,6,8\}
$$

20 experts are invited to evaluate the weights for factors. The result of design factor $u_{1}$ can be expressed as:

$$
\begin{gathered}
\hat{P}_{1}=\left\{\frac{\{[0.1,0.1] ; 0\}}{x_{1}}+\frac{\{[0.25,0.4] ; 0.55\}}{x_{2}}+\frac{\{0.45,0.75] ; 0.74\}}{x_{3}}+\frac{\{[0.2,0.6] ; 0.62\}}{x_{4}}\right\} \\
\text { From } \quad \text { Eq. } \quad(6), \quad \text { one can easily get: }
\end{gathered}
$$
$D_{1}=\{0.1,0.3325,0.672,0.448\}$, then put the result into Eq.(7), yielding the basic weight of the design factor $z_{1}=5.89114$. Similarly the other three factors' basic weights can be calculated in this way: $z_{2}=4.85632, z_{3}=5.45571, \quad z_{4}=4.88126$.

Normalize the all above $Z_{i}$, thus obtaining the weight set of 4 factors.

$$
\tilde{W}=\left(w_{1}, w_{2}, w_{3}, w_{4}\right)=(0.2794,0.2303,0.2588,0.2315)
$$

According to the reliability data analysis results of similar machine tools [10], the mission reliability degree of CNC rotary table should be in the range of 0.95 to 0.97 . Appropriately expanding the range, the alternative set is built as follows.

$$
V=\{0.94,0.95,0.96,0.97,0.98\}
$$

The 4 factors of CNC rotary table are comprehensively evaluated based on the voting model, with results as follows.

$$
\begin{array}{r}
\hat{P}_{r 1}=\left\{\frac{\{[0,0.2] ; 0.1\}}{v_{1}}+\frac{\{[0.25,0.4] ; 0.4\}}{v_{2}}+\frac{\{[0.55,0.75] ; 0.54\}}{v_{3}}+\frac{\{[0.2,0.5] ; 0.6\}}{v_{4}}+\frac{\{[0,0.3] ; 0.3\}}{v_{5}}\right\} \\
\hat{P}_{r 2}=\left\{\frac{\{[0,0] ; 0\}}{v_{1}}+\frac{\{[0.35,0.45] ; 0.5\}}{v_{2}}+\frac{\{[0.45,0.75] ; 0.45\}}{v_{3}}+\frac{\{0.25,0.65] ; 0.55\}}{v_{4}}+\frac{\{[0,0.4] ; 0.25\}}{v_{5}}\right\} \\
\hat{P}_{r 3}=\left\{\frac{\{[0,0.1] ; 0.1\}}{v_{1}}+\frac{\{[0.5,0.7] ; 0.5\}}{v_{2}}+\frac{\{[0.35,0.65] ; 0.4\}}{v_{3}}+\frac{\{[0.2,0.5] ; 0.25\}}{v_{4}}+\frac{\{[0,0.3] ; 0.2\}}{v_{5}}\right\} \\
\hat{P}_{r 4}=\left\{\frac{\{[0,0] ; 0\}}{v_{1}}+\frac{\{[0.4,0.55] ; 0.5\}}{v_{2}}+\frac{\{[0.4,0.65] ; 0.54\}}{v_{3}}+\frac{\{[0.2,0.6] ; 0.55\}}{v_{4}}+\frac{\{0,0.35] ; 0.4\}}{v_{5}}\right\}
\end{array}
$$

The evaluation matrix is calculated by Eq. (6). 


$$
\tilde{R}=\left[\begin{array}{ccccc}
0.02 & 0.310 & 0.658 & 0.380 & 0.090 \\
0 & 0.400 & 0.585 & 0.470 & 0.100 \\
0.01 & 0.600 & 0.470 & 0.275 & 0.060 \\
0 & 0.475 & 0.535 & 0.420 & 0.140
\end{array}\right]
$$

According to Eq. (11), the comprehensive evaluation index values are calculated by Matlab.

\section{$\tilde{B}=(0.0082,0.4440,0.5641,0.3828,0.0961)$}

Finally, the predicted reliability of CNC rotary table can be got by Eq.(12)

$$
P_{C}=\sum_{j=1}^{m} b_{j} v_{j} / \sum_{j=1}^{m} b_{j}=0.9607
$$

From the result above, the predicted reliability degree of $\mathrm{NC}$ rotary table during the period of periodic maintenance can be obtained as 0.9607 . Similarly, the predicted reliability degrees of other subsystems can be received based on the above steps. Combined with the system GO chart and the flow chart for reliability prediction in Fig.3, the predicted reliability degree of the whole machine can be finally obtained by the calculation using Eq.(1).

\section{CONCLUSION}

1) A fuzzy reliability prediction method based on vague set is presented in this paper, which is suitable for the situation of data deficiency and fuzzy decision information, especially in the early design stage of CNC machine tools. It is also applicable for predicting the reliability degrees of subsystems.

2) The experts' advices can be exploited extensively by this method, and the rationality of comprehensive evaluation can be improved.

3) Establishing the reliability model among different subsystems based on GO method does not need to understand the life distribution.

4) The model in the paper is highly practical. Meanwhile, it has made up the shortcomings of existing fuzzy comprehensive evaluation.

\section{REFERENCES}

[1] S. Chatterjee, S. Bandopadhyay, Reliability estimation using a genetic algorithm-based artificial neural network: An application to a load-haul-dump machine [J]. Expert Systems with Applications. 2012(39):10943-10951.

[2] D. Zhao, W. WEN, C. Duan, A Model of Aero engine Reliability Prediction Based on Fuzzy Number [J]. Journal of Aerospace Power. 2004, 19(3):320-325.

[3] Q. Hao, Z. Yang, C. Chen, F. Chen, G. Li. Reliability prediction for NC machine tool based on interval AHP [J].Journal of Jilin University(Engineering and Technology Edition). 2012, 42(4): 845-850.

[4] Y. Chen, W. Xie, S. Zeng, Functional Analysis and Physics of Failure Associated Reliability prediction [J]. Acta Aeronautica Et AstronauticaSinica.2008, 29(5):1133-1138.
[5] G. Ren, D. Wang, X. Miao, Research on the CNC reliability prediction based on grey system theory [J].Machinery Design \& Manufacture. 2010(5):191-192

[6] D. Zhao, W. Wen, C. Duan, Application of mechanical reliability prediction based on Fuzzy Theory [J].Transactions of Nanjing University of aeronautics \& Astronautics. 2004, 21(1):76-80.

[7] K.C. Hung, K.Y. Gino, Peter Chu, T.J. Warren, An enhanced method and its application for fuzzy multi-criteria decision making based on vague set [J].Computer-Aided Design. 2008 (40):447-454.

[8] Z. Shen, X. Huang, Principle and application of GO methodology [M].Beijing: Tsinghua University Press, 2004

[9] D. Zhao, Fuzzy Prediction and Allocation Techniques for Mechanical System Reliability in Early Design Stage [M].Beijing: National Defense Industry Press.2010.5.

[10] G. Zhang, Z. Xu, W. He, L. Tu, Research on Reliability Enhancement Testing Method of NC Rotary Table [J].China Mechanical Engineering. 2011, 22(8):948-951. 